\title{
Electrical Properties of the Rabbit Cortical Collecting Duct from Obstructed Kidneys after Unilateral Ureteral Obstruction
}

\author{
Effects of Renal Decapsulation
}

\author{
Shigeaki Muto and Yasushi Asano \\ Department of Nephrology, Jichi Medical School, Minamikawachi, Kawachi, Tochigi, 329-04 Japan
}

\begin{abstract}
Ureteral obstruction causes impaired salt wastage and $\mathrm{K}^{+}$ secretion in the distal nephron segments, including the cortical collecting duct (CCD). Recently, we demonstrated that conductances of $\mathrm{Na}^{+}$and $\mathrm{K}^{+}$in the apical membrane, as well as the electrogenic $\mathrm{Na}^{+}-\mathrm{K}^{+}$pump activity and the relative $\mathrm{K}^{+}$conductance in the basolateral membrane of the collecting duct cell, were inhibited in the obstructed kidney after unilateral ureteral obstruction (UUO). To examine whether the increased intrarenal pressure might be causally related to these abnormalities in the $\mathrm{CCD}$, the effects of unilateral renal decapsulation, a maneuver that partially blocks the increase in renal pressure, were evaluated with microelectrode techniques in isolated CCDs from UUO and sham-operated (control) rabbits $24 \mathrm{~h}$ after operation. Renal decapsulation had no effects on barrier voltages and conductances in the CCD from control animals. The lumen-negative transepithelial $\left(V_{T}\right)$ and basolateral membrane $\left(V_{B}\right)$ voltages as well as the transepithelial $\left(G_{T}\right)$ and the apical membrane $\left(G_{A}\right)$ conductances were decreased in the $C C D$ from UUO animals compared with control animals. Pretreatment of renal decapsulation partially corrected the decreases in $V_{T}, V_{B}, G_{T}$, and $G_{A}$ seen in the CCD from UUO animals. The changes in apical membrane voltage and $\mathbf{G}_{\mathbf{T}}$ upon addition of luminal amiloride and $\mathrm{Ba}^{2+}$, and the changes in $V_{B}$ upon addition of bath ouabain, were also decreased in the CCD from UUO animals compared with control animals. Pretreatment of renal decapsulation also partially corrected the above abnormalities seen in UUO animals, whereas it had no effect in control animals. The transference numbers for $\mathrm{Cl}^{-}\left(t_{\mathrm{Cl}}\right)$ and $\mathrm{K}^{+}\left(t_{\mathrm{K}}\right)$ in the basolateral membrane were, respectively, increased and decreased in the CCD from UUO animals compared with control animals. Pretreatment of renal decapsulation also partially corrected the changes in $t_{\mathrm{Cl}}$ and $t_{\mathrm{K}}$ seen in UUO animals, whereas it had no effect in control animals. We conclude that, in UUO animals, renal decapsulation partially corrects the inhibition of apical $\mathrm{Na}^{+}$and $\mathrm{K}^{+}$conductances as well as basolateral $\mathrm{Na}^{+}-\mathrm{K}^{+}$pump activity and relative $\mathrm{K}^{+}$conductance seen after UUO, whereas in control animals it has no
\end{abstract}

Address correspondence to Shigeaki Muto, M.D., Department of Nephrology, Jichi Medical School, Minamikawachi, Tochigi, 329-04 Japan.

Received for publication 7 March 1994 and in revised form 21 July 1994.

J. Clin. Invest.

(C) The American Society for Clinical Investigation, Inc.

0021-9738/94/11/1846/09 \$2.00

Volume 94, November 1994, 1846-1854 effect. The increased renal pressure may partly contribute to the defects in $\mathrm{Na}^{+}$and $\mathrm{K}^{+}$transport in the $\mathrm{CCD}$ from obstructed kidneys. Renal decapsulation has protective effects on impaired $\mathrm{Na}^{+}$and $\mathrm{K}^{+}$transports in the $\mathrm{CCD}$ after ureteral obstruction. (J. Clin. Invest. 1994. 94:1846-1854.) Key words: electrophysiology - unilateral ureteral obstruction - unilateral renal decapsulation - collecting duct cell

\section{Introduction}

Urinary tract obstruction is associated with a number of defects in renal function in the rat $(1-4), \operatorname{dog}(5,6)$, and humans $(7$, 8). Studies in animals with experimentally induced obstructive uropathy have shown transport defects mainly in the distal nephron segments, including the cortical collecting duct (CCD), ${ }^{1}$ characterized by impaired $\mathrm{Na}^{+}$and water reabsorption and decreased secretion of $\mathrm{H}^{+}$and $\mathrm{K}^{+}(1,3,4,8,9)$. However, the mechanisms underlying these disorders have not been fully evaluated. Only a few studies have assessed them at a segmental level (10-15). The in vitro microperfusion studies of the rabbit CCD have demonstrated that unilateral ureteral obstruction (UUO) led to decreases in the lumen-negative transepithelial voltage $(10,11)$ as well as in $\mathrm{Na}^{+}-\mathrm{K}^{+}$-ATPase activity (12) and in $\mathrm{Na}^{+}-\mathrm{K}^{+}$pump in situ turnover (13) in the CCD from obstructed rat kidneys after UUO. These observations have suggested that the collecting duct (CD) cell would be functionally impaired after ureteral obstruction, since the $C D$ cell is mainly responsible for $\mathrm{Na}^{+}$and $\mathrm{K}^{+}$transports in the CCD (16-27). Very recently, Muto et al. (25) have demonstrated that in the rabbit CCD from obstructed kidneys $24 \mathrm{~h}$ after UUO conductances of $\mathrm{Na}^{+}$and $\mathrm{K}^{+}$in the apical membrane as well as electrogenic $\mathrm{Na}^{+}-\mathrm{K}^{+}$-ATPase pump activity and relative $\mathrm{K}^{+}$conductance in the basolateral membrane of the $\mathrm{CD}$ cell were inhibited, whereas the relative $\mathrm{Cl}^{-}$conductance in the basolateral membrane was stimulated.

The mechanisms responsible for the electrical changes of the CD cell observed in the obstructed kidney after UUO are probably multifactorial. Among the factors that might be operative singly or in concert, the increased renal pressure after ureteral obstruction could be associated with impaired transport

1. Abbreviations used in this paper: $\mathrm{CCD}$, cortical collecting duct; $\mathrm{CD}$ cell, collecting duct cell; Decap, unilateral renal decapsulation; $\triangle \mathrm{EMF}$, change in basolateral membrane electromotive force due to ion substitution; $f \mathrm{R}_{\mathrm{A}}$, fractional apical membrane resistance; $\mathrm{G}_{\mathrm{A}}$, apical membrane conductance; $G_{B}$, basolateral membrane conductance; $G_{T}$, transepithelial conductance; $\mathrm{G}_{\mathrm{T} j}$, tight junction conductance; $t_{\mathrm{Cl}}$, transference number of $\mathrm{Cl}^{-}$of the basolateral membrane; $t_{\mathrm{K}}$, transference number of $\mathrm{K}^{+}$of the basolateral membrane; UUO, unilateral ureteral obstruction; $\mathrm{V}_{\mathrm{A}}$, apical membrane voltage; $V_{B}$, basolateral membrane voltage; $V_{T}$, transepithelial voltage. 
capacity for $\mathrm{Na}^{+}$and $\mathrm{K}^{+}$in the CCD from obstructed kidneys. However, there is no direct evidence for this hypothesis.

It has been reported that the renal capsule provides the major force opposing expansion of renal cortex when intrarenal pressure is increased (28). It has been demonstrated in dogs that renal decapsulation partially blocks increases in renal interstitial hydrostatic pressure associated with acetylcholine-induced vasodilation (29). Furthermore, it has been shown in Wistar rats that renal decapsulation attenuates the elevations in renal interstitial pressure and their association with natriuretic and diuretic responses observed during elevation in renal perfusion pressure or acute saline volume expansion (30). In this study, therefore, unilateral renal decapsulation (Decap) was used to partially block the increase in renal pressure. The purpose of this study was to compare the effects of unilateral renal decapsulation on electrical properties of the CD cell in the CCDs from UUO and sham-operated rabbits $24 \mathrm{~h}$ after operation, and eventually to determine whether the increased intrarenal pressure might be related to the defects in $\mathrm{Na}^{+}$and $\mathrm{K}^{+}$transports seen in the CCD from UUO animals.

In this article, we demonstrated that in UUO animals, renal decapsulation partially corrected the inhibition of apical $\mathrm{Na}^{+}$ and $\mathrm{K}^{+}$conductances as well as basolateral $\mathrm{Na}^{+}-\mathrm{K}^{+}$pump activity and $\mathrm{K}^{+}$conductance observed after UUO, whereas in control animals it had no effect. The increased renal pressure may, at least in part, contribute to the defects in $\mathrm{Na}^{+}$and $\mathrm{K}^{+}$transport in the CCD from obstructed kidneys. Renal decapsulation has beneficial effects on impaired $\mathrm{Na}^{+}$and $\mathrm{K}^{+}$transports in the CCD after ureteral obstruction.

\section{Methods}

\section{Animals and surgical procedures}

Female Japanese White rabbits weighing $1.5-2.5 \mathrm{~kg}$ were used. After a period of acclimation, the rabbits were divided into the following four groups.

Group 1 (control, intact renal capsule). 10 animals from this group underwent a sham surgical procedure of left ureteral obstruction and renal decapsulation.

Group 2 (control, left renal decapsulation). In five animals with intact ureters, a left renal decapsulation was performed.

Group 3 (UUO, intact renal capsule). 13 animals with intact renal capsules received a left ureteral obstruction.

Group 4 (UUO, left renal decapsulation). 13 animals underwent a left renal decapsulation 10 min before receiving a left ureteral obstruction.

Left ureteral obstruction was performed with sterile technique under light anesthesia with intravenous pentobarbital $(30 \mathrm{mg} / \mathrm{kg})$ by tying a 3-0 silk suture around the left ureter above the ureterovesicular junction. In control animals, the left ureter was manipulated but otherwise left intact. Left renal decapsulation was performed by incising the renal capsule with the aid of a surgical groove director so that the scalpel did not enter the renal parenchyma. The capsule was then gently removed by blunt dissection, with care taken not to transect capsular arteries. The procedure was accomplished within minutes and with only minimal manipulation of the left kidney. Usually little or no bleeding was encountered, and in all cases the bleeding stopped within $10 \mathrm{~min}$. The rabbits from all four groups were then permitted to recover from anesthesia and were returned to their cages, with free access to food and water. The rabbits were maintained on standard rabbit chow (Clea Japan, Inc., Tokyo, Japan), containing $\mathrm{Na}^{+}$of $120 \mathrm{meq} / \mathrm{kg}$ diet and $\mathrm{K}^{+}$of $400 \mathrm{meq} /$ $\mathrm{kg}$ diet, and tap water ad libitum.

\section{Isolation and perfusion of tubules}

$24 \mathrm{~h}$ after the surgery, the animals of four groups were then reanesthetized with intravenous sodium pentobarbital $(35 \mathrm{mg} / \mathrm{kg})$, and both kid- neys were removed and weighed. Slices of the coronal section 1-2-mm thick from left kidneys were made and transferred to a dish containing a cold intracellular fluid-like solution of the following composition (mM): $14 \mathrm{KCl}, 44 \mathrm{~K}_{2} \mathrm{HPO}_{4}, 14 \mathrm{KH}_{2} \mathrm{PO}_{4}, 9 \mathrm{NaHCO}_{3}$, and 160 sucrose. As described previously (20-27), this dissection medium was selected because it has been reported that intracellular fluid-like solutions are much better at preserving kidney tissue, metabolically as well as functionally. Segments of CCDs were dissected from the cortex and transferred to a bath mounted on an inverted microscope (Diaphot; Nikon, Tokyo, Japan). Each tubule was perfused in vitro according to the techniques developed by Burg et al. (31) and as modified in this laboratory for the use of intracellular microelectrodes (20-27). Since the details of the technique have been published previously (20-27), they will be presented here only briefly. Tubules were suspended between the two pipettes. The luminal perfusion rate exceeded $20 \mathrm{nl} / \mathrm{min}$ in all tubules. The distal end of the tubule was held in the collecting pipette with unpolymerized Sylgard 184 (Dow Corning Corp., Midland, MI). The tubule was perfused in the bathing chamber of $\sim 100 \mu 1$ to permit rapid exchange of the bathing solution within $5 \mathrm{~s}$. The bathing solution flowed at $5-15 \mathrm{ml} / \mathrm{min}$ from the reservoirs by gravity through a water jacket to permit the bath temperature to be regulated at $37^{\circ} \mathrm{C}$.

\section{Electrical measurements}

The transepithelial and cellular electrical properties of the tubule were measured using techniques described previously in this laboratory (2027). In brief, the transepithelial voltage $\left(V_{T}\right)$ was measured through the perfusion pipette, which was connected to one channel of a dual-channel electrometer (Duo 773; World Precision Instruments, Inc., Sarasota, FL) with a $3 \mathrm{M} \mathrm{KCl} / 3 \%$ agar bridge and a calomel half-cell electrode. The basolateral membrane voltage $\left(\mathrm{V}_{\mathrm{B}}\right)$ was measured with $0.5 \mathrm{M} \mathrm{KCl}$ filled microelectrodes, which were fabricated from borosilicate glass capillaries (GD-1.5; $1.5 \mathrm{~mm}$ OD, $1.0 \mathrm{~mm}$ ID; Narishige Scientific Laboratory, Tokyo, Japan) by using a vertical puller (PE-2; Narishige Scientific Laboratory). Both voltages were referenced to the bath and were recorded on a four-pen chart recorder (R64; Rikadenki, Tokyo, Japan). The electrical potential difference across the apical membrane $\left(V_{A}\right)$ was given by

$\mathrm{V}_{\mathrm{A}}=\mathrm{V}_{\mathrm{T}}-\mathrm{V}_{\mathrm{B}}$

Cable analysis was used to calculate the transepithelial conductance $\left(G_{T}\right)$ and the fractional apical membrane resistance $\left(f R_{A}\right)$, as described in detail previously (20-27). Constant-current pulses, $50 \mathrm{nA}(300 \mathrm{~ms}$ in duration, 10-s interval), were injected into the tubule lumen via the perfusion pipette. The $f \mathrm{R}_{\mathrm{A}}$ was estimated from the ratio of the voltage deflection across the apical membrane and the voltage deflection across the entire epithelium at the point of impalement.

The conductances of the apical and basolateral membranes $\left(G_{A}\right.$ and $G_{B}$, respectively) and the tight junction conductance $\left(G_{T_{j}}\right)$ were estimated using $2 \mathrm{mM} \mathrm{Ba}^{2+}$ in the lumen as a probe to the equation described previously $(17-19,25-27,32,33)$ :

$\mathrm{G}_{\mathrm{T}}=\left(1-f \mathrm{R}_{\mathrm{A}}\right) \mathrm{G}_{\mathrm{B}}+\mathrm{G}_{\mathrm{Tj}}$.

Ion substitution studies were conducted to determine the relative ion permselectivity of the basolateral membrane. When the ion concentration of the bathing solutions was changed, the initial peak change in $V_{B}$ was used with fast bath exchange rates $(2-5 \mathrm{~s})$ to minimize secondary effects such as changes in cellular ion activities. Voltage changes due to lowering bath $\mathrm{Cl}^{-}$and raising bath $\mathrm{K}^{+}$concentrations were corrected for liquid junction potentials with free-flowing $3 \mathrm{M} \mathrm{KCl}$ electrodes. The change in basolateral membrane electromotive force due to ion substitution ( $\triangle E M F)$ was estimated according to the following equation (25-27, 34): $\Delta E M F=\Delta V_{B}-I \cdot R_{B}$, where $\Delta V_{B}$ is the measured change in $V_{B}$ due to ion substitution and $I \cdot R_{B}$ is the change in membrane potential due to the dissipation of energy from current flowing across the basolateral membrane resistance $\left(R_{B}\right)$. As described previously (2527), the circular loop current (I) was estimated from $G_{T j}$ and the change in $\mathrm{V}_{\mathrm{T}}$ on ion substitution $\left(\Delta \mathrm{V}_{\mathrm{T}}\right)$ as $\mathrm{I}=\mathrm{G}_{\mathrm{Tj}} \cdot \Delta \mathrm{V}_{\mathrm{T}}$. The transference 
numbers, which indicate the relative portion of a specific conductance of an ion with respect to the overall conductance, were calculated according to the following equation $(25,26)$ :

$t_{\text {ion }}=\Delta \mathrm{EMF} /\left[61 \cdot \log \left(\mathrm{c}_{1} / \mathrm{c}_{2}\right)\right]$,

where $t_{\text {ion }}$ is the transference number of the respective ion, and where $c_{1}$ and $c_{2}$ are the two different ion concentrations of the specific ion used in the step-change experiments.

\section{Identification of $C D$ cells}

Cell impalements in this study were limited to CD cells. CD cells were electrophysiologically distinguished from intercalated cells according to the criteria described previously by Muto et al. (17-27). CD cells have a lower $f \mathrm{R}_{\mathrm{A}}$, higher $\mathrm{V}_{\mathrm{B}}$, apical $\mathrm{Na}^{+}$and $\mathrm{K}^{+}$conductances, and basolateral $\mathrm{K}^{+}$and $\mathrm{Cl}^{-}$conductances, whereas intercalated cells have a higher $f \mathrm{R}_{\mathrm{A}}$, lower $\mathrm{V}_{\mathrm{B}}$, a dominant basolateral $\mathrm{Cl}^{-}$conductance, and no detectable apical $\mathrm{K}^{+}$conductance. Therefore, $\mathrm{CD}$ cells were electrophysiologically identified by the depolarization of $\mathrm{V}_{\mathrm{A}}$ and the decrease in $f \mathrm{R}_{\mathrm{A}}$ upon raising the luminal $\mathrm{K}^{+}$concentration. In addition, $\mathrm{CD}$ cells showed a depolarization of $\mathrm{V}_{\mathrm{A}}$ and an increase in $f \mathrm{R}_{\mathrm{A}}$ upon addition of luminal $\mathrm{Ba}^{2+}$, a $\mathrm{K}^{+}$channel inhibitor. In sharp contrast, intercalated cells did not show any significant changes in $\mathrm{V}_{\mathrm{A}}$ or $f \mathrm{R}_{\mathrm{A}}$ upon raising the luminal $\mathrm{K}^{+}$concentration and addition of luminal $\mathrm{Ba}^{2+}$.

\section{Solutions and materials}

The composition of the control bathing and perfusing solution was (mM): $110 \mathrm{NaCl}, 5 \mathrm{KCl}, 1 \mathrm{MgCl}_{2}, 1.8 \mathrm{CaCl}_{2}, 25 \mathrm{NaHCO}_{3}, 10 \mathrm{Na}$ acetate, $0.8 \mathrm{Na}_{2} \mathrm{HPO}_{4}, 0.2 \mathrm{NaH}_{2} \mathrm{PO}_{4}, 5$ L-alanine, and $8.3 \mathrm{D}$-glucose. This control solution had an osmolality between 285 and $295 \mathrm{mosmol} /$ $\mathrm{kg} / \mathrm{H}_{2} \mathrm{O}$ and was equilibrated with $95 \% \mathrm{O}_{2} / 5 \% \mathrm{CO}_{2}$ and adjusted to $\mathrm{pH}$ 7.4 at $37^{\circ} \mathrm{C}$. In some experiments, $45 \mathrm{mM} \mathrm{Na}^{+}$was replaced with $\mathrm{K}^{+}$ or $108.6 \mathrm{mM} \mathrm{Cl}^{-}$was replaced with cyclamate.

Amiloride (Sigma Chemical Co., St. Louis, MO) was added to the luminal perfusate to achieve a final concentration of $50 \mu \mathrm{M}$. Ouabain (Sigma Chemical Co.) was used in the bath at a concentration of $10^{-4}$ $\mathrm{M}$. $\mathrm{BaCl}_{2}$ was used in the lumen at a final concentration of $2 \mathrm{mM}$.

\section{Measurements of tubular length and diameters}

Tubular lengths were measured at the end of each experiment, using a calibrated reticle in the eyepiece of the microscope. The tubules were photographed at a proximal, central, and distal site during perfusion at a magnification of 200 . Inner and outer diameters were measured at 0.05 - mm intervals along the tubule. Reported values are the average of at least five measurements. Since the tubules from the four groups were rapidly perfused at similar rates and pressures, the degree of distension of the lumen is assumed to be similar in all.

Table I. Comparison of Body and Kidney Weights among the Four Groups

\begin{tabular}{crrrc}
\hline & & & \multicolumn{2}{c}{ Kidney weight } \\
\cline { 4 - 5 } Group & $n$ & Body weight & Right & Left \\
\hline & & $k g$ & & $g$ \\
1 & 10 & $1.65 \pm 0.05$ & $6.1 \pm 0.3$ & $5.1 \pm 0.5$ \\
2 & 5 & $1.73 \pm 0.06$ & $6.4 \pm 0.1$ & $6.4 \pm 0.2$ \\
3 & 13 & $1.70 \pm 0.04$ & $6.1 \pm 0.1$ & $10.8 \pm 0.4^{* \neq}$ \\
4 & 13 & $1.67 \pm 0.02$ & $6.6 \pm 0.1$ & $11.1 \pm 0.3^{* \neq}$
\end{tabular}

Values are mean \pm SE; $n$, number of animals; $* P<0.001$ compared with the left kidney weights of group $1 ;{ }^{\ddagger} P<0.001$ compared with the left kidney weights of group 2.
Table II. Comparison of Tubular Length and Inner and Outer Diameters among the Four Groups

\begin{tabular}{ccccc}
\hline Group & $n$ & Tubular length & Inner diameter & $\begin{array}{c}\text { Outer } \\
\text { diameter }\end{array}$ \\
\hline & & $\mu m$ & $\mu m$ & $\mu m$ \\
1 & 17 & $950.0 \pm 45.7$ & $29.5 \pm 0.9$ & $39.5 \pm 1.3$ \\
2 & 14 & $1048.2 \pm 75.1$ & $29.7 \pm 0.8$ & $39.5 \pm 0.9$ \\
3 & 18 & $880.2 \pm 55.7$ & $37.6 \pm 0.9^{* \ddagger}$ & $45.8 \pm 0.7^{* \ddagger}$ \\
4 & 17 & $1051.1 \pm 43.9$ & $38.0 \pm 0.9^{* \ddagger}$ & $48.7 \pm 0.8^{* \ddagger}$ \\
\hline
\end{tabular}

Values are mean \pm SE. $n$, number of tubules; $* P<0.001$ versus group $1 ;{ }^{\ddagger} P<0.001$ versus group 2 .

\section{Statistics}

The data are expressed as mean $\pm \mathrm{SE}$. Comparisons were performed by the paired or nonpaired Student's $t$ test, one-way analysis of variance in combination with Scheffe's multiple comparison test, as needed. $P$ values $<0.05$ were considered statistically significant.

\section{Results}

\section{Comparison of body and kidney weights among the four groups}

Body and both kidney weights in four groups of animals are given in Table I. Body and right kidney weights were unchanged in the four groups. In groups 1 and 2, there were no significant differences in weights of right and left kidneys. By contrast, in groups 3 and 4, the weights of the obstructed left kidneys were significantly $(P<0.001)$ greater than those of the untouched right kidneys. In addition, the left kidney weights in groups 3 and 4 were significantly greater than those in groups 1 and 2 . There were no significant differences in the left kidney weights between groups 3 and 4 .

\section{Electrophysiological data}

The tubular length and inner and outer diameters of the CCD segments in four groups of tubules are given in Table II. Removal of left renal capsule had no effect on either inner or outer diameters in the CCD from control animals. By contrast, both inner and outer diameters of tubules from groups 3 and 4 were significantly greater than those from groups 1 and 2 . There were no significant differences of inner and outer diameters between groups 3 and 4 . The change in inner diameter was more prominent than in outer diameter in the CCD of group 3, and this structural change seen in the CCD of group 3 was not detected in group 4, despite luminal dilatation also observed in group 4.

Effects of renal decapsulation on barrier voltages and conductances of $C D$ cells from control and UUO animals. The barrier voltages of $\mathrm{CD}$ cells of tubules from four groups of animals are illustrated in Fig. 1. The lumen-negative $\mathrm{V}_{\mathrm{T}}$ (group 1: $-9.8 \pm 1.0 \mathrm{mV}, n=17$; group $2:-9.9 \pm 1.9 \mathrm{mV}, n=14)$ and $-\mathrm{V}_{\mathbf{B}}$ (group 1: $-79.4 \pm 2.2 \mathrm{mV}, n=17$; group 2: $-77.0 \pm 1.4$ $\mathrm{mV}, n=14$ ) were similar in groups 1 and 2. On the other hand, as reported previously by Muto et al. (25), both $-\mathrm{V}_{\mathrm{T}}(3.0 \pm 1.2$ $\mathrm{mV}, n=18)$ and $-\mathrm{V}_{\mathrm{B}}(-61.5 \pm 1.5 \mathrm{mV}, n=18)$ in the tubules from group 3 were significantly lower than those from group 1. In contrast to the tubules from group 3 , both $-\mathrm{V}_{\mathrm{T}}(-4.3 \pm 1.2$ $\mathrm{mV}, n=17)$ and $-\mathrm{V}_{\mathrm{B}}(-69.4 \pm 1.7 \mathrm{mV}, n=17)$ of the tubules 

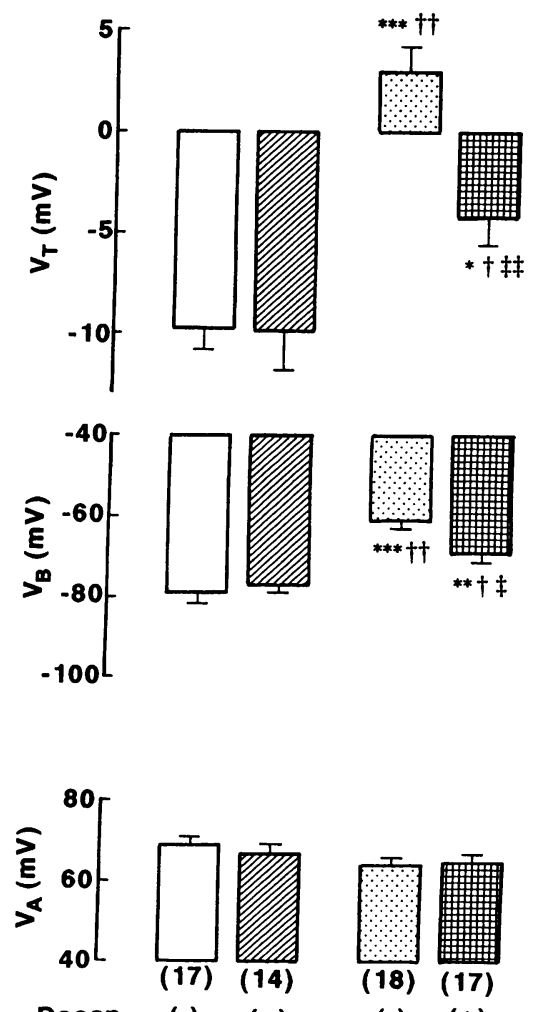

Decap
(+)
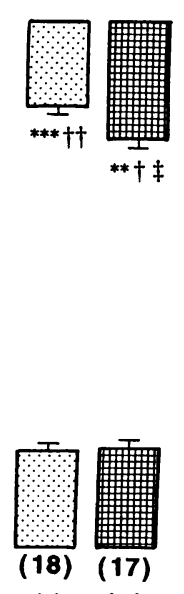

$(-) \quad(+)$

CONTROL

Figure 1. Comparison of barrier voltages among the four groups. Values are mean \pm SE. Numerals in parentheses indicate the number of experiments. ${ }^{*} P<0.05,{ }^{* *} P$ $<0.005$, and $* * * P$ $<0.001$ versus group 1 ; ${ }^{\dagger} P<0.05$ and ${ }^{\dagger+} P$ $<0.001$ versus group 2 ; ${ }^{\ddagger} P<0.05$ and ${ }^{\ddagger \ddagger} P$ $<0.005$ versus group 3 .

from group 4 were much greater than those from group 3, but were much lower than those from group 1 . These measurements of cell potentials are consistent with the notion that active electrogenic $\mathrm{Na}^{+}$transport across the basolateral membrane is inhibited upon UUO, and this inhibition seen in UUO animals is partially restored by pretreatment of renal decapsulation. The calculated $\mathrm{V}_{\mathrm{A}}$ (group 1: $69.6 \pm 2.0 \mathrm{mV}, n=17$; group 2: $67.2 \pm 2.2 \mathrm{mV}, n=14$; group $3: 64.6 \pm 1.8 \mathrm{mV}, n=18$; group 4: $65.0 \pm 1.9 \mathrm{mV}, n=17$ ) was not significantly different among the four groups.

The $f R_{\mathrm{A}}$ and barrier conductances of CD cells of tubules from four groups of animals are given in Table III. The $f \mathbf{R}_{\mathrm{A}}$ and $G_{T}$ were similar in groups 1 and 2. By contrast, as Muto et al. (25) described previously, the $f \mathrm{R}_{\mathrm{A}}$ was significantly elevated and the $G_{T}$ was significantly reduced in group 3 when compared with group 1, suggesting that UUO inhibits the conductive pathway of the apical membrane of the obstructed tu-

bule more than that of the basolateral membrane. This was evident from the fact that the $G_{A}$ was much lower in group 3 than in group 1. On the other hand, in group 4 both the $G_{T}$ and the $G_{A}$ were significantly increased compared with group 3 , although the values of the $G_{T}$ and the $G_{A}$ in group 4 did not approach those in group 1. There were no significant differences of the $G_{A}$ between groups 1 and 2 . In addition, neither $G_{B}$ nor $\mathrm{G}_{\mathrm{Tj}}$ was significantly changed among the four groups. These findings suggest that the inhibition of the conductive pathway of the apical membrane of CD cells observed after UUO is at least partially restored upon renal decapsulation.

Effects of renal decapsulation on electrical properties of the apical membrane of CD cells from control and UUO animals. As described above, pretreatment of renal decapsulation partially corrected reduction in $G_{A}$ seen in the CCD from UUO rabbits, but not from control rabbits. The first set of the studies was therefore designed to examine whether this alteration in $\mathrm{G}_{\mathrm{A}}$ is the result of a change in the $\mathrm{Na}^{+}$and/or $\mathrm{K}^{+}$conductances in the apical membrane of $C D$ cells, because the $G_{A}$ of $C D$ cells from normal rabbits is composed of a small $\mathrm{Na}^{+}$conductance and a dominant $\mathrm{K}^{+}$conductance $(16-19,21-23,25-27$, 32-34).

To examine whether the $\mathrm{Na}^{+}$conductance in the apical membrane of CD cells from UUO animals is influenced upon renal decapsulation, we added an $\mathrm{Na}^{+}$channel inhibitor, amiloride, to the luminal perfusate and compared the barrier voltages and conductances among the four groups, as shown in Table IV. Upon addition of $50 \mu \mathrm{M}$ amiloride to the perfusate, the $V_{T}$ and the $V_{B}$ in the tubules of the four groups were rapidly depolarized, resulting in a significant hyperpolarization of $V_{A}$. At that time, the $\mathrm{G}_{\mathrm{T}}$ was significantly decreased and the $f \mathrm{R}_{\mathrm{A}}$ was significantly increased in the four groups. However, the amiloride-sensitive changes in $V_{A}$ and $G_{T}$ were strikingly different among the four groups, as shown in Fig. 2. They were significantly reduced in group 3 when compared with group 1 , although they were not significantly different between groups 1 and 2 . By contrast, in group 4 they were significantly greater than in group 3, but were significantly lower than in group 1. Therefore, these results indicate that an inhibition of the $\mathrm{Na}^{+}$ conductance in the apical membrane of CD cells observed after UUO is partially corrected by pretreatment of renal decapsulation.

Next, we examined whether the apical membrane $\mathrm{K}^{+}$conductance of CD cells in the tubules from control and UUO animals is changed upon renal decapsulation. We added a $\mathrm{K}^{+}$ channel inhibitor, $\mathrm{Ba}^{2+}$, to the luminal perfusate and observed the electrical properties at the initial peak response (Table V).

Table III. Comparison of $f R_{A}$ and Barrier Conductances among the Four Groups

\begin{tabular}{|c|c|c|c|c|c|c|}
\hline Group & $n$ & $f \mathbf{R}_{\mathrm{A}}$ & $\mathbf{G}_{\mathrm{T}}$ & $\mathrm{G}_{\mathrm{A}}$ & $\mathrm{G}_{\mathrm{B}}$ & $\mathrm{G}_{\mathrm{Tj}}$ \\
\hline & & & $m S \cdot \mathrm{cm}^{-2}$ & $m S \cdot \mathrm{cm}^{-2}$ & $m S \cdot \mathrm{cm}^{-2}$ & $m S \cdot \mathrm{cm}^{-2}$ \\
\hline 1 & 16 & $0.40 \pm 0.03$ & $9.0 \pm 0.3$ & $14.8 \pm 1.6$ & $9.8 \pm 1.1$ & $3.6 \pm 0.4$ \\
\hline 2 & 10 & $0.43 \pm 0.03$ & $9.1 \pm 0.8$ & $14.9 \pm 1.5$ & $10.7 \pm 0.8$ & $3.3 \pm 0.9$ \\
\hline 3 & 15 & $0.58 \pm 0.03^{* \neq}$ & $5.5 \pm 0.3 \S^{\prime \prime}$ & $5.0 \pm 0.4^{\S \|}$ & $7.2 \pm 0.8$ & $2.7 \pm 0.2$ \\
\hline 4 & 22 & $0.48 \pm 0.03$ & $7.2 \pm 0.3^{1 \neq * *}$ & $9.6 \pm 0.9^{1 * * \pm}$ & $8.9 \pm 0.8$ & $2.6 \pm 0.8$ \\
\hline
\end{tabular}

Values are mean \pm SE. $n$, number of tubules. ${ }^{9} P<0.05,{ }^{*} P<0.005$, and ${ }^{\S} P<0.001$ versus group 1 ; ${ }^{\ddagger} P<0.05$ and $" P<0.001$ versus group $2 ;{ }^{* *} P<0.05$ versus group 3 . 
Table IV. Effects of $50 \mu M$ Amiloride in the Lumen on Barrier Voltages and Conductances at the Initial Peak Response

\begin{tabular}{|c|c|c|c|c|c|c|c|c|c|c|c|}
\hline \multirow[b]{2}{*}{ Group } & \multirow[b]{2}{*}{$n$} & \multicolumn{2}{|c|}{$\mathrm{V}_{\mathrm{T}}$} & \multicolumn{2}{|c|}{$\mathrm{V}_{\mathrm{B}}$} & \multicolumn{2}{|c|}{$\mathrm{V}_{\mathrm{A}}$} & \multicolumn{2}{|c|}{$\mathbf{G}_{\mathrm{T}}$} & \multicolumn{2}{|c|}{$f \mathbf{R}_{\mathrm{A}}$} \\
\hline & & $\mathrm{C}$ & E & C & E & C & E & C & E & C & E \\
\hline & & \multicolumn{2}{|c|}{$m V$} & \multicolumn{2}{|c|}{$m V$} & \multicolumn{2}{|c|}{$m V$} & \multicolumn{2}{|c|}{$m S \cdot \mathrm{cm}^{-2}$} & & \\
\hline 1 & 11 & $-9.4 \pm 0.9$ & $3.2 \pm 1.0 *$ & $-77.6 \pm 2.7$ & $-71.4 \pm 3.4^{*}$ & $69.3 \pm 2.5$ & $75.3 \pm 2.7 *$ & $9.1 \pm 0.6$ & $7.1 \pm 0.5^{*}$ & $0.43 \pm 0.06$ & $0.59 \pm 0.06 *$ \\
\hline 2 & 7 & $-9.4 \pm 1.7$ & $8.7 \pm 1.3^{*}$ & $-80.0 \pm 1.2$ & $-69.4 \pm 2.9^{\ddagger}$ & $70.5 \pm 1.5$ & $78.1 \pm 2.3^{8}$ & $8.5 \pm 0.8$ & $6.6 \pm 0.7 *$ & $0.48 \pm 0.04$ & $0.64 \pm 0.04 *$ \\
\hline 3 & 10 & $4.7 \pm 1.3$ & $9.8 \pm 1.8^{*}$ & $-64.0 \pm 2.1$ & $-60.6 \pm 2.2^{*}$ & $68.7 \pm 2.5$ & $70.4 \pm 2.6^{*}$ & $5.2 \pm 0.3$ & $4.4 \pm 0.3^{*}$ & $0.57 \pm 0.04$ & $0.62 \pm 0.04 *$ \\
\hline 4 & 11 & $-4.1 \pm 1.2$ & $8.1 \pm 1.6^{*}$ & $-72.2 \pm 2.3$ & $-64.4 \pm 2.5 *$ & $68.2 \pm 2.0$ & $72.6 \pm 2.6^{*}$ & $7.1 \pm 0.5$ & $5.7 \pm 0.5^{*}$ & $0.55 \pm 0.03$ & $0.68 \pm 0.03 *$ \\
\hline
\end{tabular}

Values are mean \pm SE. $n$, number of experiments; $C$, control period; $E$, experimental period. ${ }^{*} P<0.001,{ }^{8} P<0.005$, and ${ }^{\ddagger} P<0.01$ compared with the control period.

When $2 \mathrm{mM} \mathrm{Ba}^{2+}$ was added to the perfusate in the tubules of the four groups, the $V_{T}$ was rapidly hyperpolarized, and the $V_{B}$ was rapidly depolarized, resulting in a significant depolarization of $V_{A}$. At that time, the $G_{T}$ was significantly decreased, and the $f \mathrm{R}_{\mathrm{A}}$ was significantly increased in the tubules of the four groups. However, the $\mathrm{Ba}^{2+}$-sensitive changes in $V_{A}$ and $G_{T}$ were also different among the four groups, as shown in Fig. 3. As Muto et al. (25) reported previously, they were significantly lower in group 3 than in group 1 , indicating that the $\mathrm{Ba}^{2+}$-sensitive $\mathrm{K}^{+}$ conductance in the apical membrane of $\mathrm{CD}$ cells is inhibited upon UUO. In contrast to group 3, in group 4 they were significantly greater than in group 3 , but were significantly lower than in group 1. On the other hand, they were not significantly changed between groups 1 and 2 . Therefore, it is indicated that the inhibition of the $\mathrm{Ba}^{2+}$-sensitive $\mathrm{K}^{+}$conductance in the apical membrane of CD cells with UUO is partially corrected upon renal decapsulation.

Effects of renal decapsulation on electrical properties of
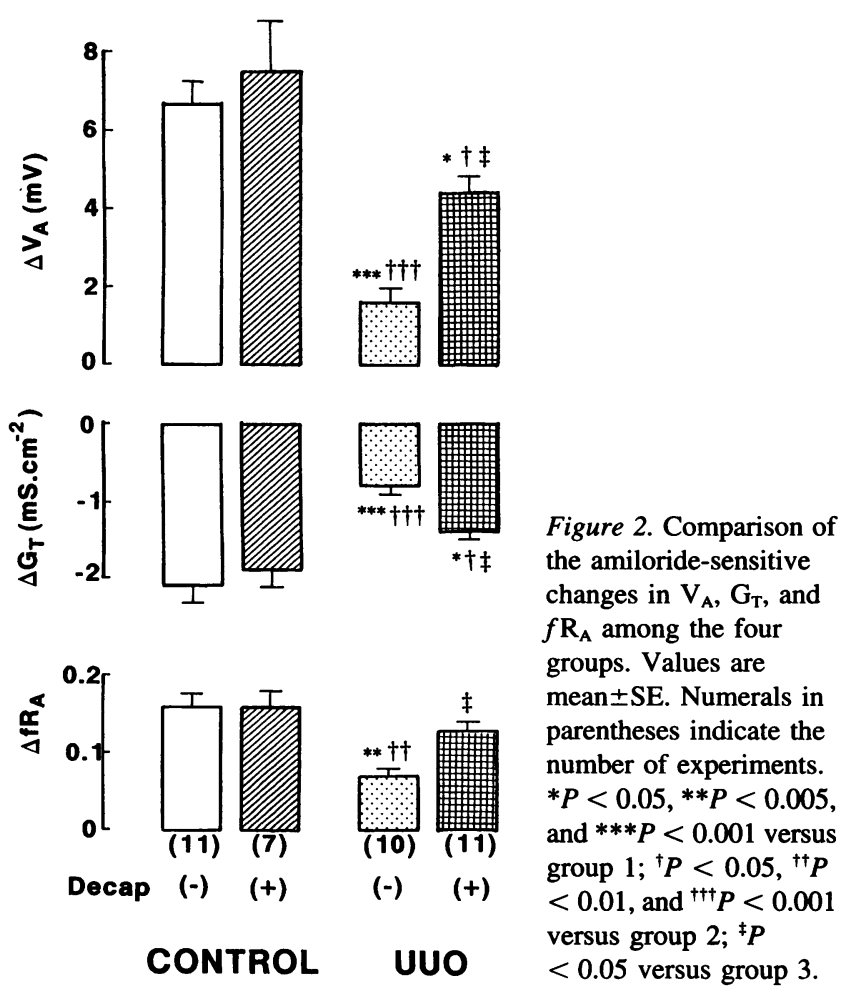

the basolateral membrane of $C D$ cells from control and UUO animals. As shown in Fig. 1, the decrease in $-V_{B}$ observed after UUO was partially prevented by pretreatment of renal decapsulation, suggesting that an inhibition of the $\mathrm{Na}^{+}-\mathrm{K}^{+}$-ATPase pump activity seen in the basolateral membrane of $\mathrm{CD}$ cells from UUO rabbits is partially corrected upon renal decapsulation. To further confirm this notion, we added an $\mathrm{Na}^{+}-\mathrm{K}^{+}$ pump inhibitor, ouabain, to the bath and observed the barrier voltages and conductances at the initial peak response. In the four groups of the tubules, addition of $10^{-4} \mathrm{M}$ ouabain to the bath caused both $V_{T}$ and $V_{B}$ to depolarize significantly without any changes in $\mathbf{G}_{\mathrm{T}}$ or $f \mathbf{R}_{\mathrm{A}}$ (Table VI). However, the initial peak changes in $V_{B}$ were also different among the four groups, as shown in Fig. 4 They were significantly lower in group 3 than in group 1. By contrast, in group 4 they were significantly greater than in group 3 , but were significantly lower than in group 1. On the other hand, they were similar in groups 1 and 2. These results are consistent with the notion that renal decapsulation partially corrects an inhibition in the $\mathrm{Na}^{+}-\mathrm{K}^{+}$ATPase pump activity in the basolateral membrane of CD cells seen in UUO animals, but not in control animals.

The conductive pathways of the basolateral membrane of CD cells from normal rabbit kidneys are composed of a dominant $\mathrm{Cl}^{-}$conductive pathway and a small $\mathrm{K}^{+}$conductive pathway $(17-20,25-27,32,34,35)$. In the basolateral membrane, the coupled influx of $\mathrm{K}^{+}$via the $\mathrm{Na}^{+}-\mathrm{K}^{+}$-ATPase pump is "recycled" via this basolateral $\mathrm{K}^{+}$conductance. Inhibition of $\mathrm{Na}^{+}-$ $\mathrm{K}^{+}$-ATPase pump is also known to cause an increase in $\mathrm{Cl}^{-}$ conductance of the basolateral membrane of $\mathrm{CD}$ cells in the rabbit $\mathrm{CCD}$ (25). Thus, the change in $\mathrm{Na}^{+}-\mathrm{K}^{+}$pump activity described above would influence both $\mathrm{K}^{+}$and $\mathrm{Cl}^{-}$conductances in the basolateral membrane, although the $G_{B}$ was not significantly changed among the four groups. When the bath $\mathrm{K}^{+}$concentration was increased from 5 to $50 \mathrm{mM}$, the basolateral membrane in the tubules of four groups was depolarized rapidly. When the bath $\mathrm{Cl}^{-}$concentration was decreased from 120 to $12 \mathrm{mM}$, the basolateral membrane in the tubules of four groups was also depolarized rapidly. We calculated the $\triangle \mathrm{EMF}$ based on the voltage deflections upon changing bath $\mathrm{K}^{+}$and $\mathrm{Cl}^{-}$and then estimated the transferance numbers of $\mathrm{K}^{+}$and $\mathrm{Cl}^{-}$of the basolateral membrane ( $t_{\mathrm{K}}$ and $t_{\mathrm{Cl}}$, respectively) (see Methods). The comparison of $t_{\mathrm{K}}$ and $t_{\mathrm{Cl}}$ among the four groups is illustrated in Fig. 5. The $t_{\mathrm{K}}$ and $t_{\mathrm{Cl}}$ in group 1 were $0.19 \pm 0.01(n=13)$ and $0.45 \pm 0.02(n=14)$, respectively. After UUO (group 3), the $t_{\mathrm{K}}$ was significantly decreased to $0.09 \pm 0.01(n=16)$, and the $t_{\mathrm{Cl}}$ was significantly increased to $0.65 \pm 0.02(n=9)$, sug- 
Table V. Effects of $2 \mathrm{mM} \mathrm{Ba}{ }^{2+}$ in the Lumen on Barrier Voltages and Conductances at the Initial Peak Response

\begin{tabular}{|c|c|c|c|c|c|c|c|c|c|c|c|}
\hline \multirow[b]{2}{*}{ Group } & \multirow[b]{2}{*}{$n$} & \multicolumn{2}{|c|}{$\mathrm{V}_{\mathrm{T}}$} & \multicolumn{2}{|c|}{$\mathrm{V}_{\mathrm{B}}$} & \multicolumn{2}{|c|}{$\mathrm{v}_{\mathrm{A}}$} & \multicolumn{2}{|c|}{$\mathbf{G}_{\mathrm{T}}$} & \multicolumn{2}{|c|}{$f \mathbf{R}_{\mathrm{A}}$} \\
\hline & & C & $\mathbf{E}$ & c & $\mathbf{E}$ & C & E & C & E & C & E \\
\hline & & \multicolumn{2}{|c|}{$m V$} & \multicolumn{2}{|c|}{$m V$} & \multicolumn{2}{|c|}{$\boldsymbol{m} V$} & \multicolumn{2}{|c|}{$\mathrm{mS} \cdot \mathrm{cm}^{-2}$} & & \\
\hline 1 & 16 & $-8.7 \pm 0.9$ & $-12.4 \pm 1.2 *$ & $-77.0 \pm 2.3$ & $-49.7 \pm 2.2^{*}$ & $68.0 \pm 2.6$ & $37.0 \pm 2.7^{*}$ & $9.0 \pm 0.3$ & $5.1 \pm 0.3^{*}$ & $0.40 \pm 0.03$ & $0.83 \pm 0.01 *$ \\
\hline 2 & 10 & $-8.5 \pm 1.4$ & $-18.1 \pm 1.8^{*}$ & $-76.2 \pm 2.7$ & $-55.1 \pm 2.8^{*}$ & $67.6 \pm 1.9$ & $37.0 \pm 2.4^{*}$ & $9.1 \pm 0.8$ & $5.2 \pm 0.8^{*}$ & $0.43 \pm 0.03$ & $0.84 \pm 0.01 *$ \\
\hline 3 & 15 & $3.6 \pm 0.9$ & $-1.6 \pm 2.0^{\ddagger}$ & $-64.0 \pm 1.7$ & $-49.2 \pm 2.0 *$ & $67.6 \pm 1.5$ & $47.6 \pm 1.3^{*}$ & $5.5 \pm 0.3$ & $3.6 \pm 0.2 *$ & $0.58 \pm 0.03$ & $0.87 \pm 0.02 *$ \\
\hline 4 & 22 & $-3.8 \pm 1.0$ & $-16.1 \pm 2.1^{*}$ & $-70.2 \pm 1.5$ & $-55.5 \pm 2.3^{*}$ & $66.3 \pm 1.6$ & $39.8 \pm 1.9 *$ & $7.2 \pm 0.5$ & $4.6 \pm 0.4^{*}$ & $0.48 \pm 0.03$ & $0.80 \pm 0.01 *$ \\
\hline
\end{tabular}

Values are mean \pm SE. $n$, number of experiments; $C$, control period; $E$, experimental period. ${ }^{*} P<0.001$ and ${ }^{\ddagger} P<0.01$ compared with the control period.

gesting that upon $\mathrm{UUO}$ the relative $\mathrm{K}^{+}$conductance is decreased and the relative $\mathrm{Cl}^{-}$conductance is increased. By contrast, in group 4 the $t_{\mathrm{K}}(0.14 \pm 0.01, n=12)$ was significantly greater than in group 3, but did not approach the value in group 1 . Furthermore, in group 4 the $t_{\mathrm{Cl}}(0.52 \pm 0.03, n=12)$ was significantly lower than in group 3 and was not significantly different from the value in group 1 . The $t_{\mathrm{K}}$ and $t_{\mathrm{Cl}}$ were similar in groups 1 and $2\left(t_{\mathrm{K}}: 0.19 \pm 0.01, n=9 ; t_{\mathrm{Cl}}: 0.46 \pm 0.03, n=8\right)$. Taken together, these results indicate that a decrease in relative $\mathrm{K}^{+}$ conductance observed after UUO is partially corrected upon renal decapsulation, whereas an increase in relative $\mathrm{Cl}^{-}$conductance observed after UUO is completely attenuated upon renal decapsulation. In addition, these changes in relative $\mathrm{K}^{+}$and $\mathrm{Cl}^{-}$ conductances seen in UUO animals after renal decapsulation were associated with a change in $\mathrm{Na}^{+}-\mathrm{K}^{+}$-ATPase pump activity.

\section{Discussion}

The results of this study provide additional information regarding the mechanisms responsible for impaired $\mathrm{Na}^{+}$and $\mathrm{K}^{+}$trans-

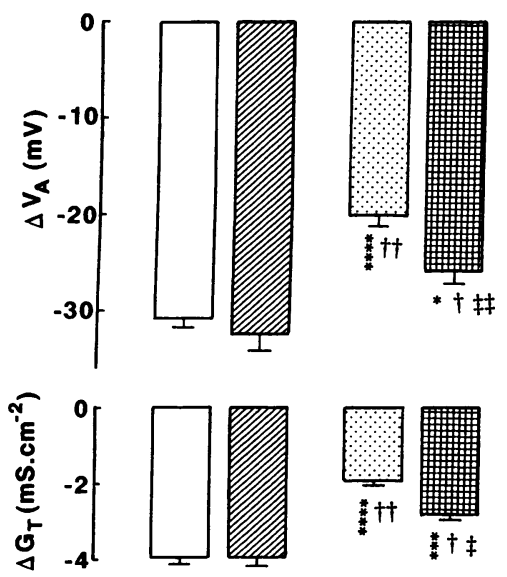

Figure 3. Comparison of the changes in $V_{A}, G_{T}$, and $f \mathrm{R}_{\mathrm{A}}$ upon addition of luminal $\mathrm{Ba}^{2+}$ among the four groups. Values are mean \pm SE. Numerals in parentheses indicate the number of experiments. ${ }^{*} P<0.05,{ }^{* *} P<0.01$, $* * * P<0.005$, and $* * * * P<0.001$ versus group $1 ;{ }^{\dagger} P<0.05$ and ${ }^{+\dagger} P<0.001$ versus group 2; ${ }^{\ddagger} P<0.05$ and ${ }^{\ddagger \ddagger} P$ $<0.01$ versus group 3 . port capacity of CD cells in the CCD of obstructed kidneys 24 $h$ after UUO. The major finding of this study is that in UUO animals renal decapsulation partially corrects the inhibition of apical $\mathrm{Na}^{+}$and $\mathrm{K}^{+}$conductances as well as basolateral $\mathrm{Na}^{+}-\mathrm{K}^{+}$ pump activity and $\mathrm{K}^{+}$conductance seen after $\mathrm{UUO}$, whereas in control animals it has no effect.

Electrical properties of the apical as well as basolateral membranes of CD cells from control and UUO animals after renal decapsulation. As Muto et al. (25) reported previously, the present study also showed that the $G_{A}$ was selectively decreased in the CCD from UUO animals. In contrast, removal of the renal capsule partially corrected the decrease in $G_{A}$ seen in UUO animals, but not in control animals. In addition, we observed that the changes in $\mathrm{V}_{\mathrm{A}}$ and $\mathrm{G}_{\mathrm{T}}$ upon addition of luminal amiloride and $\mathrm{Ba}^{2+}$ were significantly smaller in UUO animals compared with control animals. Pretreatment of renal decapsulation also partially corrected the above abnormalities seen in UUO animals, but not in control animals (Figs. 2 and 3). Taken together, these results indicate that renal decapsulation partially corrects the decreases in $\mathrm{Na}^{+}$and $\mathrm{K}^{+}$conductances of the apical membrane seen in UUO rabbits, but not in control rabbits.

As shown in Figs. 1 and 4 , both $-V_{T}$ and $-V_{B}$, as well as

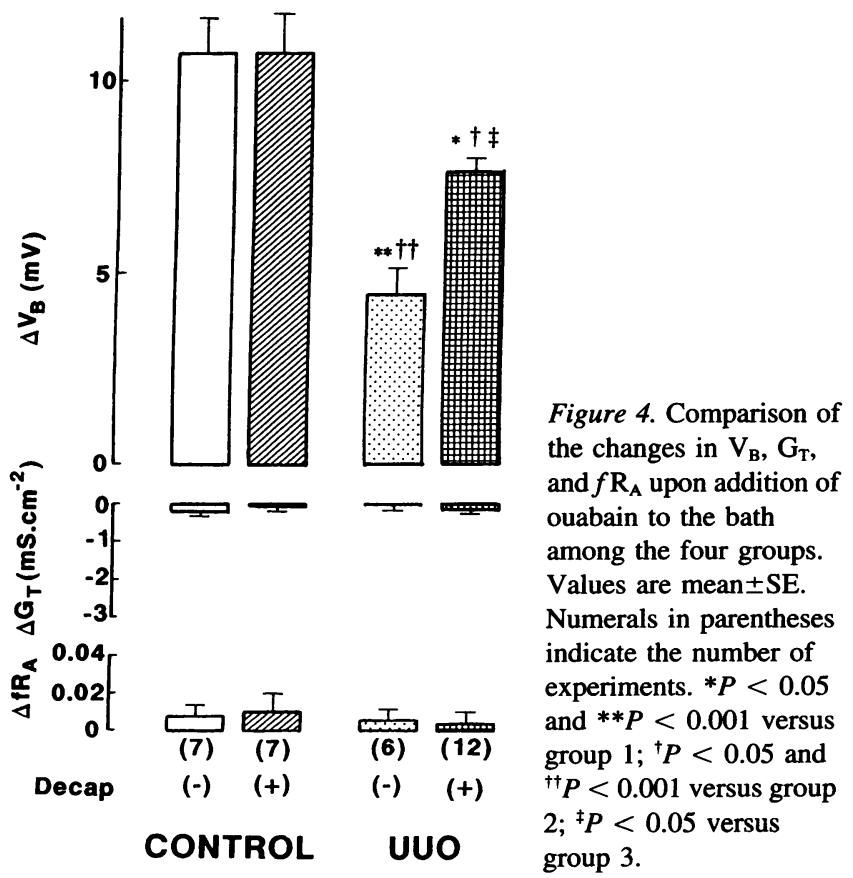


Table VI. Effects of $10^{-4}$ M Ouabain in the Bath on Barrier Voltages and Conductances at the Initial Peak Response

\begin{tabular}{|c|c|c|c|c|c|c|c|c|c|}
\hline \multirow[b]{2}{*}{ Group } & \multirow[b]{2}{*}{$n$} & \multicolumn{2}{|c|}{$V_{T}$} & \multicolumn{2}{|c|}{$\mathrm{V}_{\mathrm{B}}$} & \multicolumn{2}{|c|}{$\mathbf{G}_{\mathbf{T}}$} & \multicolumn{2}{|c|}{$f \mathrm{R}_{\mathrm{A}}$} \\
\hline & & C & E & C & E & C & E & C & E \\
\hline & & \multicolumn{2}{|c|}{$m V$} & \multicolumn{2}{|c|}{$m V$} & \multicolumn{2}{|c|}{$\mathrm{mS} \cdot \mathrm{cm}^{-2}$} & & \\
\hline 1 & 7 & $-9.3 \pm 1.5$ & $0.4 \pm 1.1^{*}$ & $-81.5 \pm 4.7$ & $-70.8 \pm 4.6 *$ & $8.9 \pm 0.3$ & $8.7 \pm 0.4$ & $0.45 \pm 0.05$ & $0.46 \pm 0.06$ \\
\hline 2 & 7 & $-8.4 \pm 1.0$ & $0.4 \pm 0.9 *$ & $-77.1 \pm 2.6$ & $-66.4 \pm 2.2 *$ & $8.4 \pm 0.3$ & $8.3 \pm 0.3$ & $0.40 \pm 0.04$ & $0.41 \pm 0.03$ \\
\hline 3 & 6 & $2.3 \pm 1.2$ & $6.2 \pm 1.2^{\ddagger}$ & $-61.8 \pm 0.9$ & $-57.3 \pm 1.2 *$ & $5.0 \pm 0.5$ & $4.8 \pm 0.5$ & $0.59 \pm 0.04$ & $0.60 \pm 0.04$ \\
\hline 4 & 12 & $-4.3 \pm 0.7$ & $2.1 \pm 0.7^{*}$ & $-67.6 \pm 1.2$ & $-59.9 \pm 1.3^{*}$ & $6.9 \pm 0.2$ & $6.8 \pm 0.1$ & $0.48 \pm 0.02$ & $0.49 \pm 0.02$ \\
\hline
\end{tabular}

Values are mean \pm SE. $n$, number of experiments; $C$, control period; $E$, experimental period. ${ }^{*} P<0.001$ and ${ }^{\ddagger} P<0.005$ compared with the control period.

the initial peak changes in $V_{B}$ upon addition of ouabain to the bath, were not altered in the CCD from control animals by renal decapsulation. On the other hand, they were significantly decreased in UUO animals compared with control animals, and the above abnormalities seen in UUO animals were partially corrected by pretreatment of renal decapsulation. These results indicate that renal decapsulation also partially corrects the inhibitory effects of UUO on basolateral $\mathrm{Na}^{+}-\mathrm{K}^{+}$pump activity, whereas it has no effect in control animals.

Using the transference numbers for $\mathrm{Cl}^{-}$and $\mathrm{K}^{+}$, we can estimate the relative $\mathrm{Cl}^{-}$and $\mathrm{K}^{+}$conductances across the basolateral membrane. In this study we found that the relative conductances of $\mathrm{Cl}^{-}$and $\mathrm{K}^{+}$were not influenced in the CCD from control animals by renal decapsulation (Fig. 5). On the other hand, the relative conductances of $\mathrm{Cl}^{-}$and $\mathrm{K}^{+}$were, respectively, decreased and increased in the CCD from UUO animals

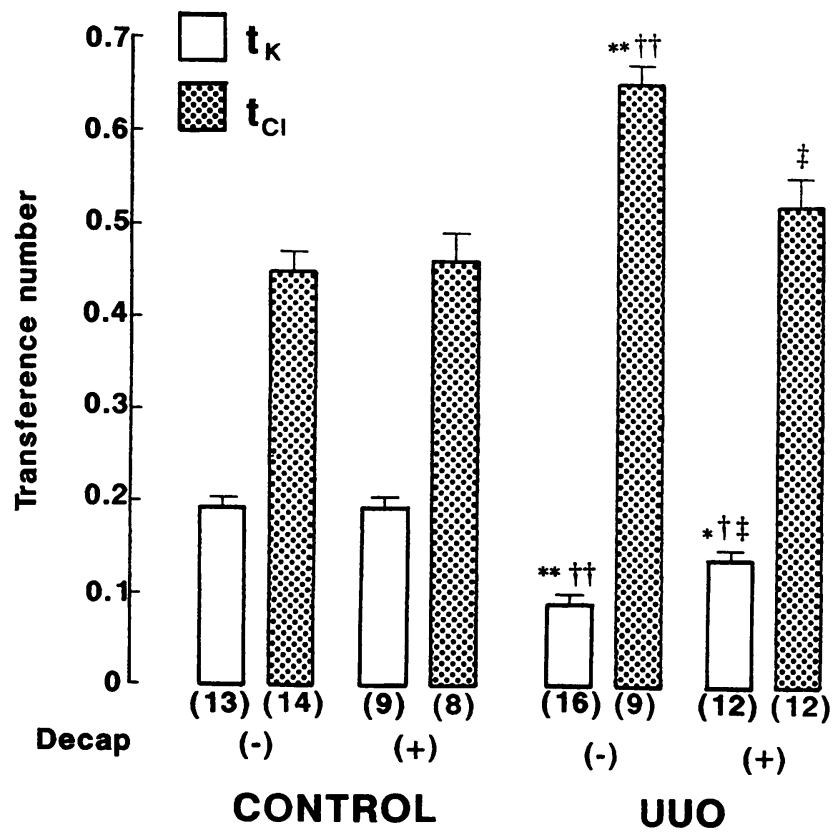

Figure 5. Comparison of the transference numbers of the basolateral membrane $\left(t_{\mathrm{K}}\right.$ and $\left.t_{\mathrm{Cl}}\right)$ among the four groups. Values are mean $\pm \mathrm{SE}$. Numerals in parentheses indicate the number of experiments. The $t_{\mathrm{K}}$ and $t_{\mathrm{Cl}}$ reflect the relative $\mathrm{K}^{+}$and $\mathrm{Cl}^{-}$conductances of the basolateral membrane, respectively. ${ }^{*} P<0.05$ and $* * P<0.001$ versus group 1 ; ${ }^{\dagger} P<0.05$ and ${ }^{\dagger \dagger} P<0.001$ versus group $2 ;{ }^{\ddagger} P<0.05$ versus group 3 . compared with control animals. In contrast to control animals, these changes in relative $\mathrm{Cl}^{-}$and $\mathrm{K}^{+}$conductances of the basolateral membrane seen in the UUO animals were partially corrected by renal decapsulation. We speculate that the changes in $\mathrm{Na}^{+}-\mathrm{K}^{+}$pump activity, in parallel with changes in basolateral membrane $\mathrm{K}^{+}$conductance seen in UUO animals with and without renal decapsulation, may possibly be associated with an alteration in $V_{B}$. Alternatively, this alteration in $V_{B}$ induces changes in relative $\mathrm{Cl}^{-}$conductance, since the $\mathrm{Cl}^{-}$channel in the basolateral membrane of $\mathrm{CD}$ cells from normal rabbit kidneys is reported to be voltage dependent at physiological potentials (36). Muto et al. (25) also reported that there is an inverse correlation between $-\mathrm{V}_{\mathrm{B}}$ and the relative $\mathrm{Cl}^{-}$conductance in CD cells from sham-operated and obstructed rabbit kidneys 24 $\mathrm{h}$ after operation. To directly demonstrate whether the changes in relative $\mathrm{K}^{+}$and $\mathrm{Cl}^{-}$conductances of the basolateral membrane seen in UUO animals are linked to the alteration in $\mathrm{V}_{\mathrm{B}}$, further studies examining the magnitude of $\mathrm{K}^{+}$and $\mathrm{Cl}^{-}$conductances of the basolateral membrane in the presence of bath ouabain will be required.

Mechanisms responsible for defects in $\mathrm{Na}^{+}$and $\mathrm{K}^{+}$transport in $C D$ cells after UUO. Among the factors responsible for defects in $\mathrm{Na}^{+}$and $\mathrm{K}^{+}$transports in the CCD after ureteral obstruction, increased renal pressure has been suggested (9-13). In this study, we found that unilateral renal decapsulation had significant effects on $\mathrm{Na}^{+}$and $\mathrm{K}^{+}$transport properties in the CCD from UUO animals, but not from control animals. These findings suggest that the effects of renal decapsulation on transport properties observed in CD cells from UUO animals might occur as a result of partial blocking of increased renal pressure, although we did not measure the renal interstitial hydrostatic pressure in control and UUO rabbits before and after renal decapsulation. This is based on the report of Hebert et al. (28) that the renal capsule provides the major force opposing expansion of renal cortex in dogs when intrarenal pressure is increased. This is also supported by the report of Hartupee et al. (29) that renal decapsulation can partially block the elevations in renal interstitial hydrostatic pressure associated with acetylcholine-induced vasodilation in dogs. It has also been shown in Wistar rats (30) that renal decapsulation partially blocks elevations in renal interstitial hydrostatic pressure and their association with pressure natriuretic and diuretic responses during increase in renal perfusion pressure or volume expansion. If the effects of in vivo intraluminal pressure on tubular diameters are preserved in the isolated $C C D$, it can be speculated that the in vivo pressure could be greater in UUO animals than control 
animals because both inner and outer diameters of tubules isolated from UUO animals (groups 3 and 4) are significantly greater than those from control animals (groups 1 and 2) (Table II). We can also speculate that in UUO animals with renal decapsulation (group 4) the in vivo pressure could be much lower than in UUO animals with intact renal capsules (group 3 ) because the flattening of the CCD epithelium due to increased intraluminal pressure was observed in the CCD from UUO animals with intact renal capsules (group 3), but this structural characteristic was not detected in UUO animals with renal decapsulation (group 4), as shown in Table II. Therefore, we conclude that the increase in renal pressure might at least partly explain the defects in $\mathrm{Na}^{+}$and $\mathrm{K}^{+}$transport in the $\mathrm{CCD}$ after ureteral obstruction. It is also possible that renal decapsulation is known to permit surface losses of renal interstitial fluid (37). Thus, we cannot rule out the possibility that surface losses could explain the present findings. It should be noted that partial blocking of increased renal pressure with unilateral renal decapsulation had demonstrable protective effects on impaired $\mathrm{Na}^{+}$ and $\mathrm{K}^{+}$transports seen in the CCD after ureteral obstruction. In the 1970s it was also reported that transplant surgeons used partial renal decapsulation of the allograft (incision of the renal capsule) to prevent possible rupture of the allograft during episodes of acute rejection $(37,38)$.

In this study, inhibition of apical $\mathrm{Na}^{+}$and $\mathrm{K}^{+}$conductances, as well as basolateral $\mathrm{Na}^{+}-\mathrm{K}^{+}$pump activity and $\mathrm{K}^{+}$conductance seen in the CCD from UUO animals, was partially but not completely corrected by renal decapsulation. In addition to increased renal pressure, therefore, a number of other factors could also play a role in affecting the $\mathrm{Na}^{+}$and $\mathrm{K}^{+}$transport in the CCD after ureteral obstruction, such as increases in renal prostaglandin production $(39,40)$, decreases in tubular flow rate (41), or resistance to aldosterone and vasopressin (42). It is also possible that alterations in one or more of these factors are also responsible for the transport defects in $\mathrm{Na}^{+}$and $\mathrm{K}^{+}$. Further studies will be required to determine the mechanisms responsible for the abnormalities in $\mathrm{Na}^{+}$and $\mathrm{K}^{+}$transport in the CCD after ureteral obstruction.

In summary, effects of unilateral renal decapsulation on $\mathrm{Na}^{+}, \mathrm{K}^{+}$, and $\mathrm{Cl}^{-}$transport properties of $\mathrm{CD}$ cells in the $\mathrm{CCD}$ have been demonstrated in UUO rabbits, but not in sham-operated rabbits. The increased renal pressure may partly contribute to the defects in $\mathrm{Na}^{+}$and $\mathrm{K}^{+}$transport in the CCD after UUO. Renal decapsulation has beneficial effects on impaired $\mathrm{Na}^{+}$and $\mathrm{K}^{+}$transports in the CCD after ureteral obstruction.

\section{Acknowledgments}

We would like to thank Ms. H. Kasakura for expert secretarial assistance in preparing the manuscript.

This work was supported in part by a grant from the Japanese Kidney Foundation (Jinkenkyukai) and the Science Research Promotion Fund from the Japan Private School Promotion Foundation.

\section{References}

1. Harris, R. H., and W. E. Yarger. 1974. Renal function after release of unilateral ureteral obstruction in rats. Am. J. Physiol. 227:806-815.

2. Thirakomen, K., N. Kozlov, J. A. L. Aruuda, and N. A. Kurzman. 1976. Renal hydrogen ion secretion after release of unilateral ureteral obstructions. Am. J. Physiol. 231:1233-1239.

3. DalCanton, A., A. Corradi, R. Stanziale, G. Maruccio, and L. Migone. 1979. Effects of 24-hour unilateral ureteral obstruction on glomerular hemodynamics in rat kidney. Kidney Int. 15:457-462.
4. Bander, S. J., J. E. Buerkert, D. Martin, and S. Klahr. 1985. Long-term effects of 24-hour unilateral ureteral obstruction on renal function in the rat. Kidney Int. 28:614-620.

5. Kerr, W. S., Jr. 1956. Effects of complete ureteral obstruction in dogs on kidney function. Am. J. Physiol. 184:521-526.

6. Jaenike, J. R., and G. A. Bray. 1960. Effects of acute transitory unilateral obstruction in the dog. Am. J. Physiol. 199:1219-1222.

7. Better, O. S., A. I. Arieff, S. G. Massry, C. R. Kleeman, and M. H. Maxwell. 1973. Studies on renal function after complete unilateral ureteral obstruction three months' duration in man. Am. J. Med. 54:234-240.

8. Battle, D., J. A. L. Arruda, and N. A. Kurzman. 1981. Hyperkalemic distal renal tubular acidosis associated with obstructive uropathy. N. Engl. J. Med. 304:373-380.

9. Klahr, S. 1983. Pathophysiology of obstructive nephropathy. Kidney Int. 23:414-426.

10. Hanley, M. J., and K. Davidson. 1982. Isolated nephron segments from rabbit models of obstructive nephropathy. J. Clin. Invest. 69:165-174.

11. Cambell, H. T., E. Bello-Reuss, and S. Klahr. 1985. Hydraulic water permeability and transepithelial voltage in the isolated perfused rabbit cortical collecting tubule following acute unilateral ureteral obstruction. J. Clin. Invest. 75:219-225.

12. Sabatini, S., and N. A. Kurzman. 1990. Enzyme activity in obstructive uropathy: basis for salt wastage and the acidification defect. Kidney Int. 37:79_ 84.

13. Kimura, H., and S. K. Mujais. 1990. Cortical collecting duct Na-K pump in obstructive nephropathy. Am. J. Physiol. 258:F1320-F1327.

14. Hwang, S.-J., M. Haas, H. W. Harris, Jr., P. Silva, S. Yalla, M. R. Sullivan, G. Otuechere, M. Kashgarian, and M. L. Zeidel. 1993. Transport defects of rabbit medullary thick ascending limb cells in obstructive nephropathy. J. Clin. Invest. 91:21-28.

15. Hwang, S. J., H. W. Harris, Jr., G. Otuechere, S. Yalla, M. R. Sullivan, M. Kashgarian, D. J. Benos, T. R. Kleyman, and M. Zeidel. 1993. Transport defects of rabbit inner medullary collecting duct cells in obstructive nephropathy. Am. J. Physiol. 264:F808-F815.

16. Koeppen, B. M., B. A. Biagi, and G. H. Giebisch. 1982. Intracellular microelectrode characterization of the rabbit cortical collecting duct. Am. J. Physiol. 244:F35-F47.

17. O'Neil, R. G., and S. C. Sansom. 1984. Electrophysiological properties of cellular and paracellular conductive pathways of the rabbit cortical collecting duct. J. Membr. Biol. 82:281-295.

18. Muto, S., G. Giebisch, and S. Sansom. 1987. Effects of adrenalectomy on CCD: evidence for differential response of two cell types. Am. J. Physiol. 253:F742-F752.

19. Muto, S., S. Sansom, and G. Giebisch. 1988. Effects of a high potassium diet on electrical properties of cortical collecting ducts from adrenalectomized rabbits. J. Clin. Invest. 81:376-380.

20. Muto, S., K. Yasoshima, K. Yoshitomi, M. Imai, and Y. Asano. 1990. Electrophysiological identification of $\alpha$ - and $\beta$-intercalated cells and their distribution along the rabbit distal nephron segments. J. Clin. Invest. 86:1829-1839.

21. Muto, S., H. Furuya, K. Tabei, and Y. Asano. 1991. Site and mechanism of action of epidermal growth factor in rabbit cortical collecting duct. Am. J. Physiol. 260:F163-F169.

22. Muto, S., M. Imai, and Y. Asano. 1993. Effect of nafamostat mesilate on $\mathrm{Na}^{+}$and $\mathrm{K}^{+}$transport properties in the rabbit cortical collecting duct. Br. J. Pharmacol. 109:673-678.

23. Muto, S., M. Imai, and Y. Asano. 1994. Mechanisms of the hyperkalaemia caused by nafamostat mesilate: effects of its two metabolites on $\mathrm{Na}^{+}$and $\mathrm{K}^{+}$ transport properties in the rabbit cortical collecting duct. Br. J. Pharmacol. 111:173-178.

24. Muto, S., M. Imai, and Y. Asano. 1993. Further electrophysiological characterization of the $\alpha$ - and $\beta$-intercalated cells along the rabbit distal nephron segments: effects of inhibitor. Exp. Nephrol. 1:301-308.

25. Muto, S., Y. Miyata, and Y. Asano. 1993. Electrical properties of the rabbit cortical collecting duct from obstructed and contralateral kidneys after unilateral ureteral obstruction. J. Clin. Invest. 92:571-581.

26. Muto, S., S. Ebata, and Y. Asano. 1994. Short-term effects of uninephrectomy on electrical properties of the cortical collecting duct from rabbit remnant kidneys. J. Clin. Invest. 93:286-296.

27. Ebata, S., S. Muto, and Y. Asano. 1992. Effects of uninephrectomy on electrical properties of the cortical collecting duct from rabbit remnant kidneys. J. Clin. Invest. 90:1547-1557.

28. Hebert, L. A., K. A. Stuart, and J. A. Stemper. 1975. Whole kidney volume/pressure relationships. Kidney Int. 7:45-54.

29. Hartupee, D. A., J. C. Burnett, Jr., J. I. Mertz, and F. G. Knox. 1982 Acetylcholine-induced vasodilation without natriuresis during control of interstitial pressure. Am. J. Physiol. 243:F325-F329.

30. Khraibi, A. A., and F. G. Knox. 1989. Effect of renal decapsulation on renal interstitial hydostatic pressure and natriuresis. Am. J. Physiol. 257:R44R48. 
31. Burg, M. B., M. Grantham, S. Abramov, and J. Orloff. 1966. Preparation and study of fragments of single rabbit nephrons. Am. J. Physiol. 210:1293-1298.

32. Sansom, S. C., and R. G. O'Neil. 1986. Effects of mineralocorticoids on transport properties of cortical collecting duct basolateral membrane. Am. J. Phys iol. 251:F743-F757.

33. Sansom, S. C., and R. G. O'Neil. 1985. Mineralocorticoid regulation of apical cell membrane $\mathrm{Na}^{+}$and $\mathrm{K}^{+}$transport of the cortical collecting duct. Am. J. Physiol. 248:F858-F868.

34. Sansom, S. C., S. Agulian, S. Muto, V. Illig, and G. Giebisch. 1989. K activity of CCD principal cells from normal and DOCA-treated rabbits. Am. J. Physiol. 256:F136-F142.

35. Sansom, S. C., E. J. Weinman, and R. G. O'Neil. 1984. Microelectrode assessment of chloride conductive properties of the cortical collecting duct. Am. J. Physiol. 247:F291-F302.

36. Sansom, S. C., B.-Q. La, and S. L. Carosi. 1990. Double-barreled chloride channels of collecting duct basolateral membrane. Am. J. Physiol. 259:F46-F52.
37. Hebert, L. A., K. A. Stuart, and J. A. Stemper. 1975. Effect of renal decapsulation on renal function. Am. J. Physiol. 229:632-639.

38. Fjeldborg, O., and C. H. Kim. 1974. Spontaneous rupture of renal transplant. Scand. J. Urol. Nephrol. 8:31-36.

39. Currie, M. G., B. B. Davis, and P. Needleman. 1981. Localization of exaggerated prostaglandin synthesis associated with renal damage. Prostaglandins. 22:933-944.

40. Ehinnery, M. A., J. O. Shaw, and N. Beck. 1982. Thromboxan $B_{2}$ and prostaglandin $\mathrm{E}_{2}$ in the rat kidney with unilateral ureteral obstruction. Am. J. Physiol. 242:F220-F225.

41. Engbretson, B. G., and L. C. Stoner. 1987. Flow-dependent potassium secretion by rabbit cortical collecting tubule in vitro. Am. J. Physiol. 253:F896F903.

42. Klahr, S., S. J. Schwab, and T. J. Stokes. 1986. Metabolic adaptation of the nephron in renal disease. Kidney Int. 13:539-546. 